\title{
Изменения NDVI как индикатор динамики экологического состояния ландшафтов (на примере восточной части Полесской провинции)
}

\author{
А. П. Гусев四 \\ Гомельский государственный университет им. Ф. Скорины, Беларусь \\ (246019, г. Гомель, ул. Советская, 104) \\ Поступила в редакиию 16.09.2019 \\ Принята к печати 26.02.2020
}

\begin{abstract}
Аннотация: Цель исследований - изучение динамики NDVI как индикатора изменений состояния широколиственно-лесных ландшафтов на региональном и локальном уровне. Maтериаль и методы. В качестве операционной территориальной единицы использован выдел рода природного ландшафта. Значения NDVI получены из продукта MOD13Q1. Рассмотрены изменения NDVI в 2000-2018 годах на территории восточной части Полесской провинции (юго-восток Беларуси). Изучены особенности динамики NDVI на тестовых участках, различающихся по характеру антропогенных преобразований. Результаты. Выявлены региональные тренды динамики NDVI. Значительная часть $(47,7 \%)$ территории региона характеризуется увеличением средних значений NDVI. Наибольший прирост NDVI произошел в пойменных ландшафтах. Локально $(4,4 \%)$ выделены участки, на которых наблюдается снижение NDVI, обусловленное, вероятно, антропогенными преобразованиями ландшафтов.
\end{abstract}

Ключевые слова: индикаторы, динамика, ландшафт, MODIS, NDVI.

\section{NDVI Changes as an Indicator of the Dynamics of the Ecological State of Landscapes (on the Example of the Eastern Part of the Polessie Province)}

\section{A.P. Gusev $\bowtie$}

\begin{abstract}
The aim of the research is to study the dynamics of NDVI as an indicator of changes in the state of deciduous-forest landscapes at the regional and local level. As an operational territorial unit, a selection of the type of natural landscape was used. NDVI values are from MOD13Q1. The changes in NDVI in 20002018 are considered in the eastern part of the Polessie province (southeast of Belarus). The features of NDVI dynamics in test areas that differ in the pattern of anthropogenic transformations are studied. The regional trends in the dynamics of NDVI are revealed. A significant part (47.7\%) of the region's territory is characterized by an increase in average NDVI values. The largest increase in NDVI occurred in floodplain landscapes. Locally $(4.4 \%)$, plots were identified where a decrease in NDVI is observed, probably due to anthropogenic transformations of landscapes.
\end{abstract}

Key words: indicators, dynamic, landscape, MODIS, NDVI.

\section{ВВЕДЕНИЕ}

Использование космической информации для диагностики состояния ландшафтов - это актуальное направление современной геоэкологии. Для решения широкого круга задач экологической оценки территорий с помощью методов дистанционного зондирования применяются вегетационные индексы, наиболее изученный и широко используемый из которых - NDVI (Normalized Difference

(ㄷ) Гусев А.П., 2020

E-mail: andi gusev@mail.ru

(c) (i) Контент доступен под лицензией Creative Commons Attribution 4.0 License.

The content is available under Creative Commons Attribution 4.0 License. 
Vegetation Index). Его, как правило, рассматривают в качестве характеристики фотосинтетически активной биомассы $[7,11]$. В различных исследованиях установлена корреляция между NDVI и первичной продукцией экосистем, причем, как валовой, так и чистой [7, 8, 9]. В работе [7] дается количественная оценка отношений между NDVI и данными по растительному покрову, которые получены с помощью измерений показателей биологического круговорота на участках, представляющих разные природные зоны. Показано, что NDVI является надежным дистанционным показателем первичной продуктивности наземных экосистем (исключение составляют горные районы и пустыни). Тесная взаимосвязь между NDVI и первичной продукцией подтверждается для разных регионов мира $[8,9]$. Сильная степень корреляции между первичной продукцией и NDVI обуславливает использование данного индекса как индикатора продуктивности и устойчивости экосистем [9].

Практическое использование NDVI как индикатора антропогенных нарушений ландшафтов ограничивается его зависимостью от климатических колебаний, состояния атмосферы в период съемки и рядом других факторов. Так, динамика NDVI зависит от колебаний климатических показателей, что установлено на примере различных регионов мира и природных зон $[2,5,6]$. Например, в степном ландшафте сезонная и многолетняя динамика NDVI в большей степени определяется колебаниями метеорологических условий, а в меньшей - изменениями величины антропогенных нагрузок [5].

Цель настоящей статьи - изучение динамики NDVI как индикатора изменений состояния широколиственно-лесных ландшафтов на региональном и локальном уровне. Решаемые задачи: 1) изучение многолетней динамики NDVI в ландшафтах Полесской провинции в 2000-2018 годы; 2) выявление основных трендов динамики NDVI; 3) изучение особенностей многолетней динамики NDVI на тестовых участках, различающихся по характеру антропогенных преобразований.

\section{ОБЪЕКТ И МЕТОДИКА ИССЛЕДОВАНИЙ}

Объект исследований - территория восточной части Полесской ландшафтной провинции, которая расположена на юге Беларуси (подзона широколиственно-лесных ландшафтов). Общая площадь изучаемого региона составляет 34,9 тысяч км². В пределах района исследований представлены такие рода ландшафтов, как водно-ледниковые составляют 35,8 \% от общей площади района; озер- но-аллювиальные - 20,7\%; аллювиальные террасированные - $17,3 \%$; пойменные $-8,5 \%$; моренно-зандровые - 8,0\%; озерно-болотные - 7,9\%; холмисто-моренно-эрозионные - $1,0 \%$; вторичноморенные $-0,7 \%$ (по классификации природных ландшафтов Беларуси [3]).

В качестве операционной территориальной единицы в нашей статье выступал выдел рода ландшафта (всего 70 выделов).

Нами использовались данные MOD13Q1, которые содержат значения NDVI, рассчитанные по результатам съемки спутника Terra (радиоспектрометр MODIS). Эти данные представляют собой растр с пространственным разрешением 250 м, скомпонованный из максимальных значений NDVI за 16 суток. Продукт MOD13Q1 взят с ресурса NASA ${ }^{1}$.

Используемый в статье вегетационный индекс рассчитывается по общеизвестной формуле: $\mathrm{NDVI}=(\mathrm{NIR}-\mathrm{RED}) /(\mathrm{NIR}+\mathrm{RED})$, где NIR - значения отражения в ближней инфракрасной зоне; RED - отражение в красной зоне спектра. Индекс - безразмерный показатель, который изменяется в диапазоне от -1 до +1 .

Для устранения влияния сезонной вариабельности NDVI для анализа использовались композиты только летнего сезона $(25.05-09.06,10.06-$ 25.06, 26.06-11.07, 12.07-27.07, 28.07-12.08, 13.0828.08). Временной охват - 2000-2018 годы.

Для выявления регионального тренда NDVI определялись статистические характеристики (среднее, медиана, стандартное отклонение) за два 5-летних периода: 2000-2004 и 2014-2018 годы. Пятилетний период был взят для устранения возможного влияния метеорологических аномалий (например, аномально сухое и жаркое лето или аномально холодное лето).

Как индикатор тренда использован показатель $\mathrm{dNDVI}=\mathrm{NDVI}_{2}-\mathrm{NDVI}_{1}$, где $\mathrm{NDVI}_{1}-$ среднее значение за 2000-2004 годы; $\mathrm{NDVI}_{2}$ - среднее значение за 2014-2018 годы. Достоверность различий между 2000-2004 и 2014-2018 годами оценивалась по критерию Вилкоксона для зависимых выборок.

Для изучения антропогенных изменений в 2000-2018 годах ландшафтов на тестовых участках использовались данные космической съемки Landsat (Landsat 4-5 TM, Landsat 8 OLI). Критерии отбора снимков: облачность - менее $10 \%$, период съемки - июль-август. Данные спутников Landsat взяты с сайта Геологический службы США².

${ }^{1}$ NASA. Доступно: https://search.earthdata.nasa.gov/ (дата обращения 1.07.2019).

2 U.S. Geological Survey. Доступно: https:// eartexplorer.usgs.gov/ (дата обращения 1.07.2019). 
Изменения NDVI как индикатор динамики экологического состояния ландшафтов (на примере восточной части Полесской провинции)

Таблица 1

Изменения средних значений NDVI в ландшафтах восточной части Полесской провинции в 2000-2018 годах

[Table 1. Changes in the average NDVI values in the landscapes of the eastern part of the

Polessye province in 2000-2018]

\begin{tabular}{|l|c|c|c|}
\hline Род ландшафта [Туре of landscape] & $\begin{array}{c}\mathrm{NDVI}_{1} \\
(2000-2004\end{array}$ гг.) & $\begin{array}{c}\mathrm{NDVI}_{2} \\
(2014-2018 \text { гг. }\end{array}$ & dNDVI \\
\hline Холмисто-моренно-эрозионный & 0,646 & 0,662 & 0,016 \\
\hline Вторично-моренный & 0,617 & 0,599 & $-0,018$ \\
\hline Моренно-зандровый & 0,706 & 0,711 & 0,004 \\
\hline Водно-ледниковый & 0,703 & 0,717 & 0,014 \\
\hline Аллювиальный террасированный & 0,716 & 0,738 & 0,022 \\
\hline Озерно-аллювиальный & 0,719 & 0,738 & 0,020 \\
\hline Озерно-болотный & 0,713 & 0,733 & 0,020 \\
\hline Пойменный & 0,704 & 0,731 & 0,027 \\
\hline Весь регион & 0,706 & 0,724 & 0,018 \\
\hline
\end{tabular}

Атмосферная коррекция, привязка, оцифровка, зональная статистика растров выполнены в QGIS 2.14.

\section{РЕЗУЛЬТАТЫ И ИХ ОБСУЖДЕНИЕ}

Изменения NDVI отражают динамику растительного покрова (зеленой фитомассы) на земной поверхности. Увеличение NDVI интерпретируется как результат роста фитомассы в ландшафте, а снижение - обратного процесса. Высокая степень корреляции NDVI с величиной чистой первичной продукции, установленная для разных природных зон, позволяет считать этот вегетационный индекс надежным индикатором продуктивности ландшафтов. Исходя из этого, временная динамика NDVI диагностирует изменения продуктивности, которая является важнейшим экологическим параметром ландшафтов.

Изучение динамики NDVI для территории региона в целом показывает рост средних значений индекса в 2000-2018 годах. Однако, положительный тренд нарушается в отдельные годы. Например, резкое увеличение средних значений NDVI в 2001 и 2009 году, а снижение - в 2015-2016 годах. Если сравнивать 2000 и 2018 годы, то средние значения NDVI увеличились на 0,08 . При сравнении 2001 и 2018 года окажется, что средние значения, наоборот, снизились на 0,01. Для сглаживания таких колебаний целесообразнее сравнивать 5-летние интервалы.

Средние значения индексов для двух временных интервалов были рассчитаны для каждого выдела рода ландшафтов. Для выяснения статистической достоверности величины dNDVI был применен критерий Вилкоксона. Все выделы были классифицированы на три группы: 1) достоверной снижение NDVI (dNDVI $<0, \mathrm{p}<0,05) ; 2)$ различия между двумя интервалам не достоверны (p>0,05); $3)$ достоверное увеличение NDVI (dNDVI $>0$, $\mathrm{p}<0,05)$.

В таблице 1 приведены средние значения NDVI по родам ландшафтов Полесской провинции на двух временных интервалах и разность dNDVI. За исключением вторично-моренного ландшафта, во всех других ландшафтах dNDVI >0, т.е. наблюдается рост значений вегетационного индекса.

Наибольший прирост характерен для пойменных ландшафтов (dNDVI=0,027). Для пойм разных рек этот показатель изменяется в пределах от 0,013 (пойма Днепра) до 0,045 (пойма Ствиги притока Припяти). В низменных аллювиальные террасированные, озерно-аллювиальные и озерноболотные ландшафты, характеризующихся относительно высокой лесистостью (40-50\%), NDVI увеличился на 0,020-0,022. В разных выделах водно-ледниковых ландшафтов dNDVI колеблется в значительных пределах (от $-0,022$ до 0,055 ), а в среднем составил 0,014. В моренно-зандровых ландшафтах - от $-0,018$ до 0,031. В холмисто-моренно-эрозионных ландшафтах (Мозырьская гряда) NDVI увеличился на 0,016, а во вторично-моренных ландшафтах, наоборот, уменьшился на 0,018 .

Оценка статистической достоверности отличий показала, что для 47,7\% территории характерен достоверный рост NDVI, а на 4,4\% территории достоверное снижение. На половине территории статистически достоверные изменения NDVI отсутствуют (таблица 2).

Причиной регионального повышения NDVI и соответственно продуктивности ландшафтов, вероятно, может являться потепление климата на юге 
Результаты оценки трендов динамики NDVI

[Table 2. The results of the assessment of trends in the dynamics of NDVI]

\begin{tabular}{|l|c|c|c|}
\hline \multirow{2}{*}{ Род ландшафта [Tуре of landscape] } & \multicolumn{3}{|c|}{$\begin{array}{c}\text { Тренд динамики NDVI } \\
\text { (\% от общей площади ландшафта) } \\
\text { [NDVI Dynamics Trend } \\
\text { (\% of the total landscape area)] }\end{array}$} \\
\cline { 2 - 4 } & $\begin{array}{c}\text { Увеличение } \\
\text { [Increase] }\end{array}$ & $\begin{array}{c}\text { Heт изменений } \\
\text { [No change] }\end{array}$ & $\begin{array}{c}\text { Снижение } \\
\text { [Decrease] }\end{array}$ \\
\hline Холмисто-моренно-эрозионный & 0,0 & 100,0 & 0,0 \\
\hline Вторично-моренный & 0,0 & 0,0 & 100,0 \\
\hline Моренно-зандровый & 12,2 & 62,6 & 25,2 \\
\hline Водно-ледниковый & 33,5 & 61,7 & 4,8 \\
\hline Аллювиальный террасированный & 73,9 & 26,1 & 0,0 \\
\hline Озерно-аллювиальный & 52,7 & 47,3 & 0,0 \\
\hline Озерно-болотный & 57,2 & 42,8 & 0,0 \\
\hline Пойменный & 79,4 & 20,6 & 0,0 \\
\hline Весь регион & 47,7 & 47,9 & 4,4 \\
\hline
\end{tabular}

Беларуси. Так, на территории Белорусского Полесья за последние 20-25 лет по сравнению с периодом 1881-1990 годов средние температуры января и февраля выросли на $2,5^{\circ}$, марта - на $2,0^{\circ} \mathrm{C}$, июля и августа - на $1,3-1,4^{\circ} \mathrm{C}$. Годовая сумма температур выше $10^{\circ} \mathrm{C}$ в 2006-2013 годах практически на всей территории Белорусского Полесья превысила 2600 градусов [4].

Однако, как видно из полученных результатов, динамика NDVI неоднородна в пространстве: часть территории характеризуется достоверным повышением, а часть, наоборот, - достоверным снижением средних значений NDVI. Так, статистически достоверное снижение NDVI характерно для всей территории вторично-моренного ландшафта, 25,2\% территории моренно-зандровых ландшафтов и $4,8 \%$ территории водно-ледниковых ландшафтов. В пределах выделов других родов ландшафтов такого процесса не зафиксировано.

Видно, что статистически достоверное увеличение имеет место на 79,4\% площади пойменных, 73,9\% площади аллювиальных террасированных, $57,2 \%$ площади озерно-болотных, 52,7\% площади озерно-аллювиальных ландшафтов. В водноледниковых ландшафтах рост NDVI достоверен только на $33,5 \%$, а в моренно-зандровых - 12,2 \% площади (таблица 2).

Одним из важных факторов, влияющих на динамику NDVI, выступают антропогенные преобразования ландшафтов, сопровождающиеся деградацией растительного покрова. Для выяснения вероятных причин изменений NDVI на территории Полесской провинции нами были выбраны тестовые участки, на которых долговременная динамика ландшафтов изучалась с привлечением данных дистанционного зондирования (Landsat) и наземных методов.

Тестовые участки представляли собой как различные рода ландшафтов, так и типичные для локального уровня ландшафтно-экологические ситуации: 1) расширение застроенных земель за счет сельскохозяйственных, болотных и лесных ландшафтов; 2) восстановление растительного покрова в зоне отселения; 3) фоновые природные процессы в зональных лесных ландшафтах (таблица 3).

Три тестовых участка представляют новые микрорайоны города Гомеля, застройка которых активно осуществлялась в 2010-2018 годах. Микрорайон «Новая жизнь» (жилая многоэтажная застройка) возводился на месте сельскохозяйственных угодий моренно-зандрового ландшафта в 2015-2018 годах. Микрорайон «Шведская горка» застраивался на намывном массиве в пойме реки Сож с 2010 года (до начала застройки здесь была пустошь с разреженной луговой и рудеральной растительностью). Микрорайон «Южный» занимает осушенный лесоболотный массив аллювиального террасированного ландшафта. Многоэтажное строительство началось в 2008-2009 годах на месте лугов и кустарников. Из таблицы 3 видно, что строительство двух микрорайонов («Новая жизнь» и «Южный») вызвало статистически достоверное ( $<<0,001)$ снижение NDVI. В микрорайоне «Шведской горки» снижение статистически не достоверно ( $>>0,05)$, что обусловлено, вероятно, сравнительно небольшими изменениями общего проек- 
Изменения NDVI на тестовых участках

[Table 3. NDVI Changes in Test Sites]

\begin{tabular}{|c|c|c|c|c|}
\hline $\begin{array}{c}\text { Тестовый участок } \\
\text { [Test Site] }\end{array}$ & $\begin{array}{c}\text { Особенности } \\
\text { антропогенного } \\
\text { воздействия } \\
\text { [Features of } \\
\text { Anthropogenic } \\
\text { Impact] }\end{array}$ & $\begin{array}{c}\mathrm{NDVI}_{1} \\
(2000-2004 \text { гг.) }\end{array}$ & $\begin{array}{c}\mathrm{NDVI}_{2} \\
(2014-2018 \text { гг.) }\end{array}$ & dNDVI \\
\hline $\begin{array}{l}\text { Микрорайон «Новая } \\
\text { жизнь» г. Гомеля } \\
\left.\text { (площадь } 0,2 \text { км²) }^{2}\right)\end{array}$ & $\begin{array}{l}\text { Застройка } \\
\text { сельскохозяйст } \\
\text { венных угодий }\end{array}$ & 0,725 & 0,635 & $-0,090$ \\
\hline $\begin{array}{l}\text { Микрорайон «Шведская } \\
\text { горка» г. Гомеля }\left(0,5 \text { км}^{2}\right)\end{array}$ & $\begin{array}{l}\text { Застройка } \\
\text { намывного } \\
\text { массива }\end{array}$ & 0,350 & 0,334 & $-0,016$ \\
\hline $\begin{array}{l}\text { Микрорайон «Южный» } \\
\text { г. Гомеля }(0,4 \text { км²) }\end{array}$ & $\begin{array}{l}\text { Застройка } \\
\text { осушенного } \\
\text { массива }\end{array}$ & 0,618 & 0,466 & $-0,152$ \\
\hline $\begin{array}{l}\text { Выведенные из оборота } \\
\text { сельскохозяйственные } \\
\text { угодья в зоне отселения } \\
\text { Ветковского района } \\
\left(2,4 \mathrm{~km}^{2}\right)\end{array}$ & $\begin{array}{l}\text { Восстановитель } \\
\text { ная сукцессия } \\
\text { растительности }\end{array}$ & 0,711 & 0,824 & 0,113 \\
\hline $\begin{array}{l}\text { Массив } \\
\text { широколиственного леса } \\
\text { в Ченковском } \\
\text { лесничестве }\left(0,2 \mathrm{kм}^{2}\right)\end{array}$ & $\begin{array}{l}\text { Антропогенное } \\
\text { воздействие } \\
\text { отсутствует }\end{array}$ & 0,793 & 0,832 & 0,039 \\
\hline $\begin{array}{l}\text { Массив } \\
\text { широколиственного леса } \\
\text { в Национальном парке } \\
\text { «Припятский» }\left(2,5 \text { км}^{2}\right) \\
\end{array}$ & $\begin{array}{l}\text { Антропогенное } \\
\text { воздействие } \\
\text { отсутствует }\end{array}$ & 0,838 & 0,882 & 0,044 \\
\hline
\end{tabular}

тивного покрытия растительности (до застройки - $30 \%$, после застройки - 25\%). В двух других микрорайонах проективное покрытие растительности снизилось в 5-10 раз.

Следующий тестовый участок представлял бывшие сельскохозяйственные угодья, которые были выведены из оборота в связи высоким радиоактивным загрязнением в начале 1990-х годов. На заброшенных пашнях и лугах стала развиваться восстановительная сукцессия [1], в ходе которой в 2010-х годах значительная часть (более $70 \%$ ) территории покрылась березовыми и сосновыми лесами, а также кустарниками. Процесс восстановления лесной растительности индицируется значительным приростом NDVI на этом участке (таблица 3 ).

Два тестовых участка представляют массивы зональных широколиственных лесов (дубово-грабовых с кленом, липой, ясенем, вязом), где отсутствуют антропогенные воздействия, вызывающие деградацию древесных ярусов. Указанные масси- вы находятся в пределах охраняемых территорий (таблица 3). Видно, что здесь имеет место увеличение NDVI (отличия достоверны с $\mathrm{p}<0,01$ ). Вероятно, что положительный dNDVI в данном случае, вероятно, обусловлен потеплением климата, которое вызвало рост продуктивности ненарушенных широколиственных лесов.

Поскольку рост застроенных и нарушенных земель (т.е. территорий с низким проективным покрытием растительности) хорошо фиксируется в изменении NDVI в пределах тестовых участков, то можно предположить, что этот антропогенный процесс влияет и на региональном уровне. Косвенным подтверждением этой гипотезы служит тот факт, что в пределах выделов родов ландшафтов, в которых отмечен отрицательный dNDVI, находятся города Гомель и Речица.

\section{ЗАКЛЮЧЕНИЕ}

Таким образом, на значительной части $(47,7 \%)$ изучаемого региона в 2000-2018 годах наблюдает- 
ся увеличение NDVI, что индицирует рост продуктивности ландшафтов и может оцениваться как благоприятная ландшафтно-экологический тенденция, т.е. направленность смен экологических состояний или ситуаций. В пределах отдельных выделов вторично-моренного, моренно-зандрового и водно-ледникового ландшафтов $(4,4 \%$ площади региона) средние значения NDVI и соответственно продуктивность снизились, что указывают на негативную ландшафтно-экологическую тенденцию. Критерий dNDVI может рекомендоваться как индикатор современных ландшафтноэкологических тенденций на региональном и локальном уровнях.

\section{СПИСОК ЛИТЕРАТУРЫ}

1. Гусев А.П. Растительный покров антропогенных ландшафтов в зоне отселения Чернобыльской АЭС // Поволжский экологический журнал, 2004, № 3, c. $246-251$.

2. Курганович К. А., Голятина М. А. Пространственно-временной отклик NDVI на изменение климатических характеристик в Забайкальском крае за период 20002014 гг. // Вестник Забайкальского государственного университета, 2015, № 9, с. 10-20.

3. Логинов В.Ф. Климатические условия Беларуси за период инструментальных наблюдений // Наука и инновации, 2016, № 9, с. 25-29.

4. Марцинкевич Г.И. Ландшафтоведение. Минск, Издательство БГУ, 2007. 206 с.

5. Рулев А.С., Канищев С.Н., Шинкаренко С.С. Анализ сезонной динамики NDVI естественной растительности Заволжья Волгоградской области // Современные проблемы дистанционного зондирования Земли из космоса, 2016, т. 13, № 4, с. 113-123.

6. Цепелев В.Ю., Паниди Е.А., Торлопова Н.В., Бобков А. А. Использование характеристик растительного покрова таежной зоны для мониторинга климатических изменений XXI в. // Ученые записки Российского государственного гидрометеорологического университета, 2015, №4 0, с. 221-234.

7. Box E. O., Holben B.N., Kalb V. Accuracy of the AVHRR Vegetation Index as a predictor of biomass, primary productivity and net $\mathrm{CO}_{2}$ flux // Vegetatio, 1989, vol. 80, p. 71-89.

8. Phillips L. B., Hansen A.J., Flather C. H. Evaluating the species energy relationship with the newest measures of ecosystem energy: NDVI versus MODIS primary production // Remote Sensing of Environment, 2008, vol. 112, p. 4381-4392.

9. Yengoh G.T. et al. The use of the Normalized Difference Vegetation Index (NDVI) to assess land degradation at multiple scales: a review of the current status, future trends, and practical considerations. Lund University Centre for Sustainability Studies, LUCSUS, 2014, 80 p.

\section{REFERENCES}

1. Gusev A.P. Rastitel'nyy pokrov antropogennykh landshaftov v zone otseleniya Chernobyl'skoy AES [Vegetation cover of anthropogenic landscapes in the resettlement zone of the Chernobyl NPP]. Povolzhskiy ekologicheskiy zhurnal, 2004, no. 3, pp. 246-251. (In Russ.)

2. Kurganovich K. A., Golyatina M. A. Prostranstvenno-vremennoy otklik NDVI na izmeneniye klimaticheskikh kharakteristik v Zabaykal'skom kraye za period 20002014 gg. [Spatio-temporal response of NDVI to changes in climatic characteristics in the Trans-Baikal Territory for the period 2000-2014]. Vestnik Zabaykal'skogo gosudarstvennogo universiteta, 2015, no. 9, pp. 10-20. (In Russ.)

3. Loginov V.F. Klimaticheskiye usloviya Belarusi za period instrumental'nykh nablyudeniy [Climatic conditions of Belarus for the period of instrumental observations]. Nauka i innovatsii, 2016, no. 9, pp. 25-29. (In Russ.)

4. Marcinkevich G. I. Landshaftovedenie [Landscape science]. Minsk, BGU Publ., 2007. 206 p. (In Russ.)

5. Rulev A.S., Kanishchev S.N., Shinkarenko S.S. Analiz sezonnoy dinamiki NDVI yestestvennoy rastitel'nosti Zavolzh'ya Volgogradskoy oblasti [Analysis of the seasonal dynamics of NDVI natural vegetation of the Volga region of the Volgograd region]. Sovremennyye problemy distantsionnogo zondirovaniya Zemli iz kosmosa, 2016, t.13, no. 4, pp. 113-123. (In Russ.)

6. Tsepelev V. Yu., Panidi A., Torlopova N. V., Bobkov A. A. Ispol'zovaniye kharakteristik rastitel'nogo pokrova tayezhnoy zony dlya monitoringa klimaticheskikh izmeneniy XXI v. [Using the characteristics of the vegetation cover of the taiga zone to monitor climate changes in the 21 st century]. Uchenyye zapiski Rossiyskogo gosudarstvennogo gidrometeorologicheskogo universiteta, 2015, no. 40, pp. 221-234. (In Russ.)

7. Box E. O., Holben B. N., Kalb V. Accuracy of the AVHRR Vegetation Index as a predictor of biomass, primary productivity and net $\mathrm{CO}_{2}$ flux. Vegetatio, 1989, vol. 80, pp. 71-89.

8. Phillips L.B., Hansen A.J., Flather C.H. Evaluating the species energy relationship with the newest measures of ecosystem energy: NDVI versus MODIS primary production. Remote Sensing of Environment, 2008, vol. 112, pp. 4381-4392.

9. Yengoh G.T. et al. The use of the Normalized Difference Vegetation Index (NDVI) to assess land degradation at multiple scales: a review of the current status, future trends, and practical considerations. Lund University Centre for Sustainability Studies (LUCSUS), 2014, 80 p. 


\section{КОНФЛИКТ ИНТЕРЕСОВ}

Автор декларирует отсутствие явных и потенциальных конфликтов интересов, связанных с публикацией настоящей статьи.

\section{Гусев Андрей Петрович}

кандидат геолого-минералогических наук; доцент, декан геолого-географического факультета Гомельского государственного университета им. Ф. Скорины, геолого-географический факультет, г. Гомель, Беларусь, ORCID: https://orcid.org/0000-0002-1169-1172, e-mail: andi_gusev@mail.ru

\section{CONFLICT OF INTEREST}

The author declares no information of obvious and potential conflicts of interest related to the publication of this article.

Andrei P. Gusev

Cand. Sci. (Geol.-Mineral.), Assoc. Prof., Dean of the Geological and Geographical Faculty at F. Skorina Gomel State University, Gomel, Belarus, ORCID:

https://orcid.org/0000-0002-1169-1172, e-mail:

andi_gusev@mail.ru 